\title{
Research on the incentive-restricted mechanism of the Chinese engineering cost consultation enterprises in China
}

\author{
Huashan Wang ${ }^{1, a}$ \\ 1. School of Management, Tianjin University of Technology, Tianjin 300384, China; \\ a. shantjlg@163.com
}

Keywords: Construction cost consultation; The incentive-restricted mechanism; Entrusted agency

\begin{abstract}
The problem of low credit exists between engineering cost consultation enterprises in China. The main reason is that the incentive constraints mechanism has not been established. Therefore, this article design the incentive constraints mechanism.
\end{abstract}

\section{INTRODUCTION}

At present, Trust of engineering cost consultation enterprises in China is very low, The reason is that incentive mechanism and risk constraint mechanism has not yet been established. Human-oriented management is widespread in society, The project cost professional is faced with incentive problems, The owner can inspire construction cost professionals, It also can come from internal consulting enterprises. Only establish effective incentive mechanism, Play the enthusiasm of professionals, cost consultation company could complete customer's trust. At the same time, Establish risk constraint mechanism, reduce mistakes of professionals, or reduce the loss value, All this is necessary.

\section{INCENTIVE OF THE OWNER AND CONSULTING THE PRINCIPAL-AGENT RELATIONSHIP-CONSTRAINT MECHANISM ANALYSIS}

2.1 The principal-agent relationship between owner and consulting

When the owner prepare to investment the project, They are very concerned about the three goals: Cost, time and quality, They want to achieve the lowest price, the shortest time, the best quality service. To achieve the unity of economy and efficiency.

However, owners' lack of professional knowledge and experience, Undertake the risk of blind decision and being deceived in the case of asymmetric information. With the help of the professionals, the project can get professional management, to make up for the owner on major defects and reduce endogenous transaction cost. Professionals have quality engineering consulting, they received a good professional education, knowledge about the project construction work program. In the process of signing a contract, professionals can carry out project planning, preparation, bidding, Finally to choose the appropriate contractor. At the same time, the professionals can avoid adverse selection: after signing the contract, supervise project on behalf of the owner, to prevent the occurrence of moral hazard, guides the work of the contractor. Principal-agent relationship between the owner and the contractor is double: the owner-consultancy-professionals. First of all, The owner will choose consulting company of poor qualification without knowing the actual situation of circumstances. The second, due to information asymmetry between the owner and consulting company, consulting company will cheat owners, thus reduce the work income. What is more serious is that consultancy, cheating the owners with the contractor. Therefore, properly handle the entrusted agency relationship between the owner and consulting company and relationship between consulting company internal personnel Is critical, It is worth to explore and research.

2.2 Causes of principal-agent problems between the owner and consulting company

The principal-agent problem is common in economic life, engineering cost consultation enterprises can solve the principal-agent problems. Along with the increase of the chain in the deal, Principal-agent problems between the owner and consulting appeared again. Principal-agent problems put forward by S.Ross at the earliest.And then, Mirrlees and Stiglitz developed the theory. 
Principal-agent relationship is a kind of contract in the theory. Under this contract, the principal authorized agent engaged in some activities. Contract mechanism promote the agent to strive for client interests. The reason for the existence of the principal-agent problem is information asymmetry between the parties, information cost and supervision cost. As shown in figure 1 .

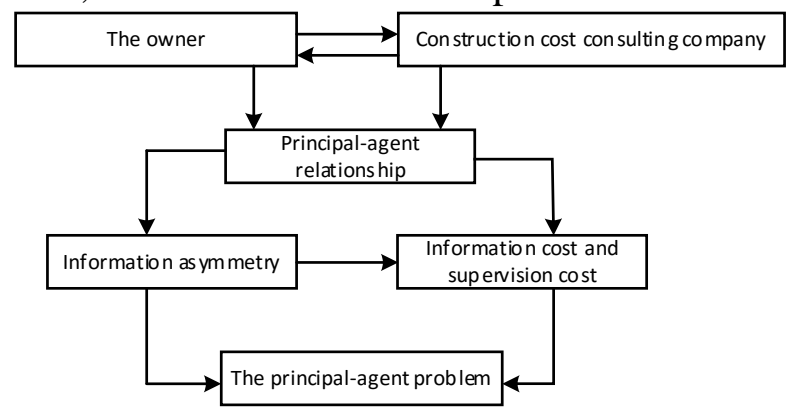

Figure 1 The causes of principal-agent problems

In the project including a consulting party, There exist information asymmetry, information cost, the supervisory cost,consulting the pursuit of their own benefit maximization. All of these lead to the principal-agent problems. The behavior of the consulting industry may deviate from the requirements of the owner. Consultation is the focus of the principal-agent problems.In solving the problem of principal-agent, Incentive and constraint consulting company and the employee is very important. In the end, consulting professionals can maximize its own interests, also can realize the best interest of the owner.

2.3 Analysis of incentive compatibility mechanism between owner and consulting company

The mechanism of incentive compatibility constraint including selection mechanism, evaluation mechanism and incentive mechanism, as shown in figure 2.



Figure 2 Game model of incentive constraint

About the incentive, traditional information complete economics think there are two types of incentives for enterprise or individual1. Private property belongs to the way of property rights incentive, price belongs to the way of profit incentives. Inadequate information economics thinks there are four kinds of incentives: Private property, price, contract and credit. Contract motivates people through reward and punishment, it motivate people to abide by the contract, it is also a kind of negative incentives. Contract emphasizes to comply with convention. Reputation is also a kind of incentives, as the information asymmetry, competition can't lower the price. Consumers believe that credit is a kind of quality guarantee. To solve the principal-agent problem between the landlord and consulting unit, we need to do three aspects of the preparation: The first is to choose the appropriate cost consultation company refer to the prestige degree; The second is to evaluate and measure consulting firm performance and level of effort; Third is to incentive cost consultation company through the contract. Consulting firm to realize own effectiveness maximization, At the same time, the owner can realize own effectiveness maximization.

2.4 Analysis of employee incentive problems in the consulting company

Engineering cost consulting firm is usually entrusted by the customer, provides intelligence services to customers.Cost consultation company completely with knowledge as a resource of the enterprise, and produces high value-added products. Cost consultation enterprises employees belong 
to the knowledge staff. The knowledge staff is different from that of ordinary employees. They not only called for the remuneration commensurate with their contributions, but also focus on inner satisfaction and their own development. Therefore, to find the real demand for consulting professionals is very important to analysising incentive mechanism.

\subsubsection{Hierarchy theory of needs from Maslow}

Maslow is a famous American humanistic psychologist. He divided the man's demand into five level: Physiological needs, security needs, social demand, respect demand, self-actualization needs. He also pointed out that demand is growing. When the low-level needs are met, high-level requirements become the pursuit of goals. As shown in figure 3.

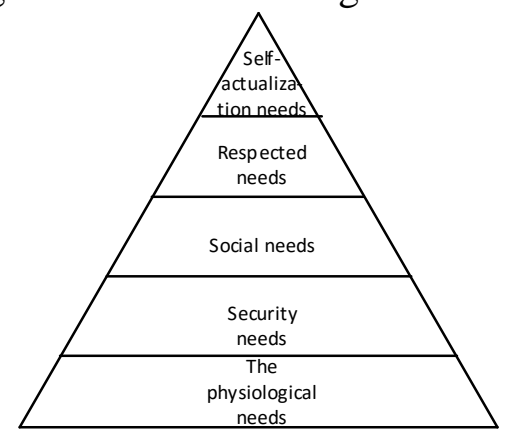

Figure 3 hierarchy need theory of Maslow

2.4.2 The empirical research from knowledge management expert $\mathrm{F} \cdot \mathrm{M} \cdot \mathrm{K}$. Tampoe

$\mathrm{F} \cdot \mathrm{M} \cdot \mathrm{K}$.Tampoe thought that the first four factors for knowledge staff concern is individual growth(account for $34 \%$ of the total), work independent wealth(account for $31 \%$ of the total), business success(account for $28 \%$ of the total) and money(account for $7 \%$ of the total).

\subsection{Engineering cost consulting firm external incentive constraint mechanism}

\subsubsection{Market environment and social environment}

(1) Perfect each rules and regulations

The perfect legal system, ethics, contract constraint is the guarantee of professionals to abide by the professional spirit. Therefore, the government departments and industry associations should focus on strengthening the construction of laws and regulations system. Industry association should set up a blacklist system. Industry association should review cost consultation enterprises, and practicing personnel qualifications, certificate of ability, reputation, performance, etc. And review the unqualified units included in the blacklist. Industry associations should be supplementary punishment mechanism, and constraint cost consultation enterprises and practitioners.

(2) Improve the feeing standard of industry

Industry charging standards directly affect the enthusiasm of cost consultation enterprises and professionals. Consulting company can not get due reward under the lower industry charging standard, and prone to moral problems. Therefore, the government department should improve the industry take appropriate fee standards. Charging standard should be set by the industry association in the industry association gradually improve the situation. In order to safeguard the economic interests of the professionals.

\subsubsection{The owner's incentive}

Incentive constraint mechanism mainly by reputation mechanism and contract mechanism to implement for the owner. When choosing a consulting firm, reputation play a role. For example prequalification. When review the tender, evaluation experts should focus on technical part, rather than business. In terms of contract incentive, industry should improve charging standard, also can adopt the way of cost plus fee. In this process, the terms of the contract must be kept confidential, and motivate consulting unit.

\subsection{The incentive-restricted mechanism of engineering cost consultation enterprises}


The incentive-restricted mechanism of engineering cost consultation enterprises is very important for professionals and the quality of consulting results. It can be divided into enterprise organization incentive, reward motivation, achievement motivation and career incentives. Supporting the implementation of constraint mechanism, for example the blacklist system and performance evaluation.

\subsubsection{Enterprise organization form}

In the western developed countries and Hong Kong, the project cost generally in the form of a partnership enterprise. There are three kinds of forms of partnership: unlimited partnership, limited partnership and limited liability partnerships. In the limited liability partnership, partners have general liability, but not jointly and severally liable. As a result, most of the cost consultation companies adopt the partnership model. Unlimited liability to motivate every partner, serious and responsible work in the process of practice. The client is glad to give the job to these companies. This is also rely on reputation mechanism for incentive. At present, the world famous libby and weining xie company adopt this way of partnership. These companies are adding new partners. Through the transfer of equity,construction cost consulting company could attract outstanding professionals to join in the enterprise.

The partnership should be promoted cost consultation enterprises in China. Partnership form can incentive and constraint professionals. Companies can survive With the help of credit and strength. At present, there only be general partnership in China. In the process of the continuous development of the consulting market, we should push forward the form of limited liability partnerships. Error of professionals is inevitable, so joint and several liability to make enterprises are not stable. Limited liability partnership can effectively motivate partners. At the same time, we can learn from foreign experience, and constantly choose talent to join to the partner.

\subsubsection{Reward incentive}

Reward incentive is mainly project bonus incentive in engineering cost consultation enterprises. Project bonus is the additional payment of compensation, the purpose is to motivate employees overfulfilled task. The incentive system has two benefits: One is to promote employees to ensure the project schedule, but improve project quality and level.

\subsubsection{Achievement motivation}

(1) Honor incentive

Honor is a symbol of achievement and contribution, at the same time it also can reflect their own value. Honor incentive including positive praise, praise, encourage, and awarded the title of honor. Professionals are knowledge workers. They are different from ordinary employees in the level of education, social relations, the nature of work and values. So, they have more sense of honor(Including the collective sense of honor and personal sense of honor).

(2) ginseng incentive

Modern human resource management research and practice show that knowledge workers have requirements and desire of manageing and making decision. So, the staff involved in management can arouse the enthusiasm of them. Through participation, the staff can form a sense of belonging and identity and a sense of achievement. To further meet the requirements of their self-esteem and self-actualization needs.

\subsubsection{Personal growth and career incentives}

Construction cost professionals focus on individual's growth. First of all, we should pay attention to the employees' human capital investment. And improve the mechanism of talent training, provide continuing education opportunities for employees. Personal growth and career incentives can enhance the level of the organization's human resources. At the same time, he also can make excellent employees become more prominent. This mechanism can also reserve high level management, management or technical personnel.

\subsubsection{Matching constraint mechanism}


Form a complete set of constraints can promote the stable operation of incentive mechanism. If ignore these form a complete set of constraints, incentive mechanism will face many difficulties and obstacles.

(1) The performance evaluation system

Performance evaluation is the premise and foundation of effective incentive,it also can provides the incentive standard and scale. Incentive mechanism needs closely integrated performance evaluation system. In the engineering cost industry, the content of the performance evaluation mainly includes professional skills, communication skills, team work, leadership, and ethics.

(2) Establish enterprise blacklist system

Performance evaluation of unqualified employees should be to join blacklist. Bonuses, welfare, promotion of blacklisted employees will be affected. If personal violation of professional ethics, customer loss, employees should be a demerit or even fired.

\section{CONCLUSION}

Construction cost professionals provide intelligence services, result is of high added value. Resolve the principal-agent problem between owners and consulting units can play the enthusiasm of professionals. Professionals will be better service to the society. Therefore, we must establish the social environment restraint mechanism(including perfecting the laws and ethics) and supporting mechanism(including blacklist system and cultivating professional ethics). Establish an effective incentive among owners, consulting institutions and professionals can make professionals have sense of honor and pride. Professionals will have higher moral quality.

\section{REFERENCE}

[1]. Chen,Weike\&Yan Ling\&Yin Yilin.2002.Challenges faced by the consultancy service and the development idea after entering the wto[J], Science and technology management. (3):47-49.

[2]. Li,Hua. 1997. International engineering contracting management profile(The first edition)[M],Bei Jing: China building industry press.

[3]. Ma,Hong.2002. The construction management and construction to deal with the WTO strategy in China(The first edition)[M],Bei Jing: China building industry press.

[4]. Steger ritz. 1997. economics(The first edition)[M].Bei Jing: Renmin university of China publishing house.

[5]. Yi,Xianrong.1998.Trading behavior and contract choice(The first edition)[M],Bei Jing: Chinese academy of social sciences.

[6]. Zhang,Weiying.2000. Game theory and information economics(The second edition)[M],Shang Hai: Shanghai people's publishing house.

[7]. Tao,Changqi.1998. Information economics(The second edition)[M]Bei Jing: Economic science press.

[8]. Yin,Yilin \& Yin,Li.2002.Engineering cost management comparison between mainland China and Hong Kong(The first edition)[M],Tian Jin: Nankai university press.

[9]. Yao,Xiaomei.2003.How to motivate knowledge workers[J],Corporate research, (19):59-61.

[10]. Zhang,Ping\&Yin,Yilin.2003.Theoretical thinking on the development of China's engineering cost consulting[J], The railway engineering cost management, (6):8-10. 